\title{
Perspectives
}

\section{BICS-CALP: An Introduction for Some, a Review for Others}

Hetty Roessingh

Over the past few years, I have often been invited to speak to various audiences on topics related to the development of English-language proficiency, most recently as the dinner speaker (May 14, 2004) for the SCENES conference in Saskatoon. The audience response and the kinds of questions asked led me to wish to share the framework that I have adopted, some visual representations that illustrate the key concepts embedded in the framework, and some research that supports the use of this framework as helpful in explaining the development of English-language proficiency. The following is a brief introduction for some and a review for others. I have adopted Cummins' (1982) metaphor of an iceberg to illustrate the BICSCALP continuum, and I have adapted Cummins' original framework-in my view at least - to fit better with the iceberg metaphor and the available research. This is as always a work in progress: we have so much yet to learn!

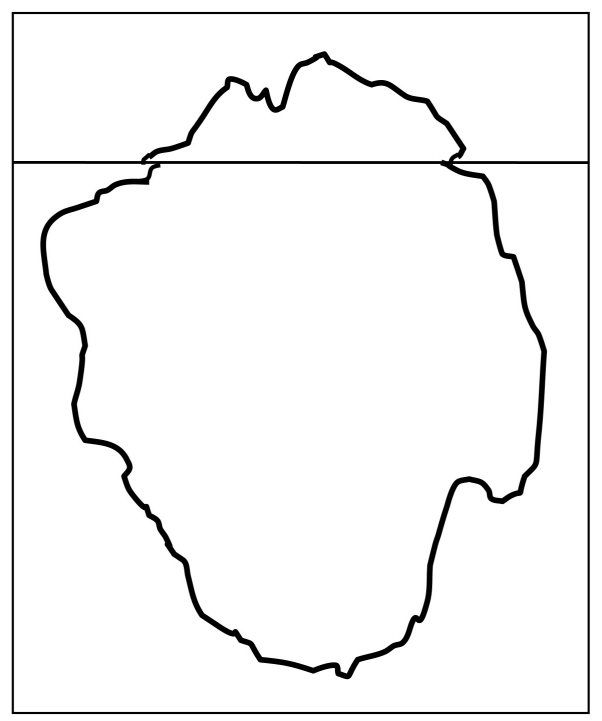

Figure 1. 


\section{The Iceberg Metaphor}

This image neatly illustrates the above-the-surface language (Basic Interpersonal Communication Skills, BICS) and the vastness of the underlying proficiency below the surface that is referred to as Cognitive Academic Language Proficiency (CALP). Like an iceberg, BICS may represent only about 10\% of the overall proficiency of an academically competent learner. The key to understanding the relationship between the above- and below-the-surface features includes understanding the role of first-language proficiency and age on arrival. "The younger the better" is a myth, as I show below. For other images of iceberg, just go to Google, click on images and ask for icebergs. There is one spectacular photograph that is just right for illustrating the concept that the metaphor explains: geocities.yahoo.com.br/.../ leituras/ icebergs.htm

Here's another great image. http://marine.rutgers.edu/herring/ iceberg/berg0013/index.htm

\section{BICS-CALP: A Developmental Continuum Organized Around Four Quadrants}

Cummins' (1982) framework highlights the role of context as fundamental to supporting children's language and literacy development. Context is represented on the horizontal axis of the framework. The cognitive demands of

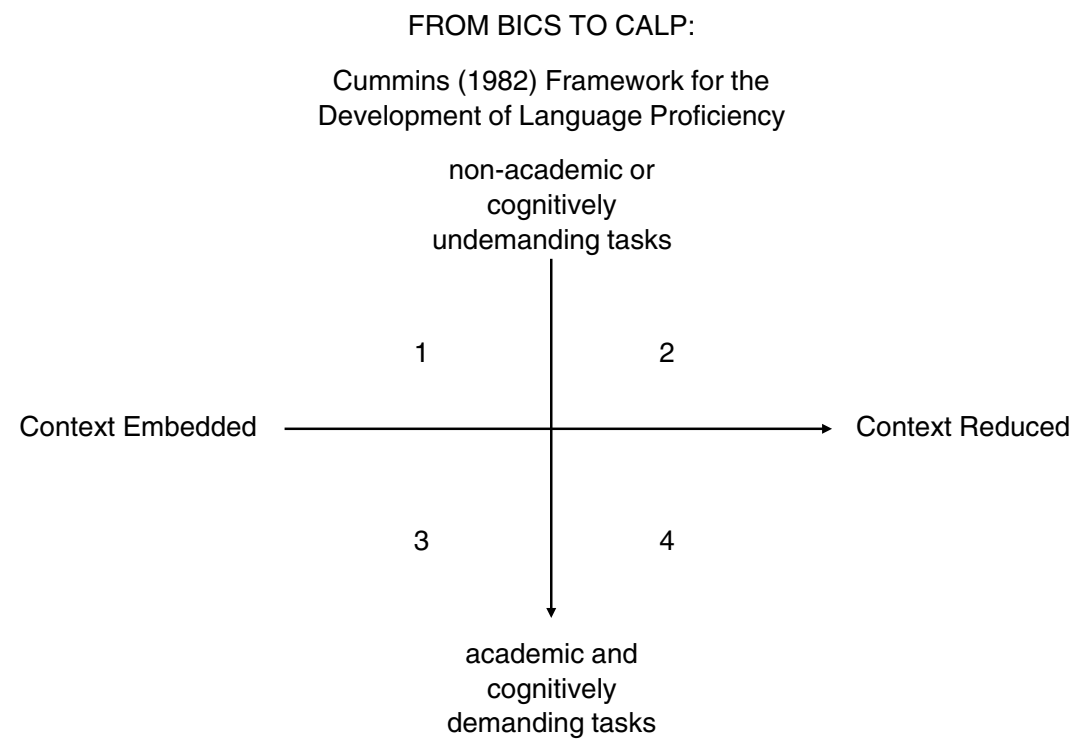

Figure 2. 
language are represented on the vertical axis. I have adapted the framework as shown in Figure 3,

If this framework is overlaid onto the iceberg image, we begin to understand the challenge of developing CALP.

Figure 3 gives information for each of the four quadrants. The reader might wish to overlay this onto the iceberg as well to get an idea of the depth of the below-the-surface proficiency required to do the cognitive push-ups required for academically demanding tasks.

- survival "chunks"

- simple grammar forms

- high-frequency vocabulary, family, clothes, food, money: face-to-face interactions

- "here and now" language: 1,000-2,500 words. Learners must personalize, internalize, and automatize these building blocks. They need to hear them hundreds and hundreds of times

\section{Cognitively Undemanding}

\section{Context}

Embedded

- transitioning to curriculum-related content

- manipulatives

- visual representations

- shift from learning to read, to reading to learn (GE 5)—to GE 7: reading strategies

- thematic units: disasters, heroes, Blue Jeans

- ESL learner has 3,000 high-frequency words, some academic words (AWL) and some common vocabulary ... maybe 8,000 words.

- "there and then" language and thought: can access with scaffolded supports-IMAGES!
- initial reading skills

- writing for personal needs: notes, lists, recipes, group-constructed text (LEA)

- common vocabulary: sports, hobbies, celebrations

- begin to integrate grammar and vocabulary: mini-themes

- "my lived experience": 2,500-5,000 words

2

Context

4

Reduced

- "the educated imagination": ideas I can access only through language itself

- Abstract thought: metaphor, symbolism, idioms, imagery

- Extensive use of reading and writing in academic genres (essays, debates)

- GE 7-9+

- 12,000 words + (compare to L1 speakers with at least 40,000 words and heading toward 100,000 by the end of grade 12)

\section{Cognitively demanding}

Figure 3. From BICS to CALP: Cummins' (1982) framework for the development of language proficiency. 
The first two quadrants represent BICS: the language of "here and now" and "my lived experiences." Quadrant 3 is an important transitional quadrant as learners shift from learning to read to reading to learn and includes "there and then" language. Quadrant 4 is characterized by the acquisition of metaphoric competence. Perhaps the most important thing to note is the ever-widening gap in vocabulary size that will forever impede the academic progress of ESL learners of all ages. This is why strategies are so important to ESL learners: they can begin to acquire them once they have an estimated reading age of grade equivalent (GE) 5 and the critical mass of vocabulary for fluent reading is in place. My guess is somewhere around 10,000-12,000 words, and this includes the 3,000-5,000 high-frequency words, the beginnings of the academic word list (AWL), and a few thousand common, but not high-frequency, words.

I chose the image of an iceberg because it depicts two peaks similar to those of the learner acquiring English-language proficiency. Dual threshold theory (Cummins, 1996) posits that when both languages eventually reach equal levels and there is a large below-the-surface mass, benefits accrue to those individuals over their unilingual counterparts.

However, note that the left-hand peak is smaller: again, a good image to illustrate the shrinking or melting away of L1 almost immediately from the day the immigrant child or teenager sets foot in Canada and begins to learn English (DeVries, 1999). Few people ever reach full bilingual proficiency: there is usually an imbalance of L1 and L2. The important factor is the depth below the surface that must be developed in either L1 or L2 for learners to reach their academic potential.

\section{Some Frequently Asked Questions}

1. How many words does a typical (native speaker (NS) 6-year-old have when he or she gets to school? Moskowitz (1978), in a study that is still widely cited, puts the figure at around 2,500. The child acquires about 3,000 words a year for the first several years of school. Then suddenly, once the child has acquired a critical mass of vocabulary and begins to read independently at around GE 4-5, vocabulary size seems to grow exponentially. Clearly children who read a great deal gain the academic edge. But direct vocabulary instruction in context is equally important and, of course, crucial for the ESL learner.

2. How fast do ESL learners pick up the language? There is general agreement that BICS-level language (above the surface) can be acquired in about two years for all ages on arrival and various L1. They acquire this language in fairly incremental steps after the so-called silent period is breached. But after BICS-level language has been acquired, the distances to the next benchmark or threshold become greater and more difficult to reach. Watt and Lake (2004) have recently released a fascinating study 
of adult rates of acquisition. I have looked at this complicated question too (Roessingh \& Kover, 2003). Quality and duration of ESL programming is crucial. I am beginning to think that one never outgrows his or her ESL-ness in the first generation.

3. Isn't there some way of accelerating the pace? ESL kids just don't have the time for language to catch up to the cognitive demands of school! The idea of looking for strategies to accelerate the pace or short cuts of some kind has attracted the attention of various researchers, and of course of policymakers who would like to limit the funding for ESL programs. Older-arriving students can transfer what they already know from L1 into English, an efficient process. But whenever the ESL learner outgrows his or her first language and must then acquire both English and the associated new conceptual information together, the learning curve starts to look sluggish. For older arrivals this may happen in the second or third year of university, and for younger arrivals it seems to be a never-ending catch-up game.

4. OK, but lots of NS never make it to quadrant 4 either. What's the big deal? You're right. Lots of NS don't make that final shift-in Piagetian terms-from concrete to formal operations, and most have a good quality of life in their adult years. But since 1985, Canada's immigration policy has attracted skilled workers, professionals, and business-class immigrants, the "brain gain." Their profile (and that of their children) suggests that they either have already acquired the underlying proficiency in L1 and should be able to make this leap in English (given instructed support at, say, adult benchmark 8 and higher), or that their children would have made this leap in L1 had they not immigrated at an early age. The plight of the youngest learners is perhaps the most devastating because many appear to acquire neither L1 nor L2 to the level required to do the cognitive push-ups in school (Roessingh \& Kover, 2002). This is an enormous loss of intellectual capital today and human resource potential for the future when we need to maintain our competitive position in the global economy. We have all heard far too many stories of electrical engineers driving taxis, cleaning, or working in the fast food sector, including one in today's Calgary Herald (Sindhi, 2004).

5. So what is an ideal age to immigrate? The small-scale studies we have conducted seem to suggest that age 15-16 (grade 10 placement) is a good age if the student comes with an intermediate level (reading GE 5) of English-language proficiency acquired from studying English as a foreign language (EFL) and assuming that they have an intact educational background in L1. The underlying proficiency developed at this point seems to transfer readily (i.e., the 40,000 words and the associated concepts and higher-order thinking skills: synthesis, 
reasoning, analysis, and so forth-that are typical for a learners in L1 of that age), they understand the concept of metaphor, they have acquired cultural capital (albeit from another culture, they understand what it is), and they usually have good study habits. There is a distinct dynamism to their learning trajectory that the younger-arriving ESL learners lack. Nevertheless, most ESL learners can benefit from ESL support in high school (750 contact hours can have a tangible effect) to reach the estimated threshold for postsecondary school studies, whether university or technical school. As they outgrow their L1 in this setting, further support would benefit many of these learners. One never stops being an ESL learner, it seems.

6. So it really all boils down to vocabulary? There is no doubt that the vocabulary deficit among ESL learners plays an enormous role in their academic success. In fact this is a good place to "close the loop" for today. Why not come to my vocabulary development presentation, and we can carry on this conversation then?

\section{The Author}

Hetty Roessingh has long been an ESL practitioner in the K-12 school system in Alberta. In 2000 she moved to the Faculty of Education in the University of Calgary where she works in the MEd TESL program teaching courses in methods, materials, and curriculum. She can be reached at hroessin@ucalgary.ca.

\section{References}

Cummins, J. (1982). Bilingualism and minority language children. Toronto, ON: OISE Press.

Cummins, J. (1996). Negotiating identities: Education for empowerment in a diverse society. Ontario, CA: California Association for Bilingual Education.

DeVries, J. (1999). Foreign born language acquisition and shift. In S. Halli \& L. Dreidger (Eds.), Immigrant Canada: Demographic, economic and social challenges (pp. 261-281). Toronto, ON: University of Toronto Press.

Moskowitz, B. (1978). The acquisition of language. Scientific American, November, pp. 82-96.

Roessingh, H., \& Kover, P. (2002). Working with younger-arriving ESL learners in high school English: Never too late to reclaim potential. TESL Canada Journal, 19(2), 1-20.

Roessingh, H., \& Kover, P. (2003). Variability of ESL learners' acquisition of cognitive academic language proficiency: What can we learn from achievement measures? TESL Canada Journal, 21(1), 1-21.

Sindhi, S. (2004, May). Overqualified in Calgary: How two Chinese engineers came to Calgary and got work as a waitress and a factory worker. Calgary Herald, p. A15.

Watt, D., \& Lake, D. (2004). Benchmarking adult rates of second language acquisition: How long and how fast? Edmonton, AB: Alberta Learning, Language Training Programs and Citizenship and Immigration Canada. 